\title{
Marital status independently predicts gastric cancer survival after surgical resection--an analysis of the SEER database
}

\author{
Rong-liang Shi ${ }^{1,2,3, *}$, Qian Chen ${ }^{1, *}$, Zhen Yang ${ }^{1}$, Gaofeng Pan ${ }^{1}$, Ziping Zhang ${ }^{1}$, \\ WeiHua Wang ${ }^{1,4}$, Shaoqun Liu ${ }^{1}$, Dongbin Zhang ${ }^{1}$, Daowen Jiang ${ }^{1,4}$ and Weiyan Liu ${ }^{1}$ \\ ${ }^{1}$ Department of General Surgery, Minhang Hospital, Fudan University, Shanghai, People's Republic of China \\ ${ }^{2}$ Department of Head and Neck Surgery, Fudan University Shanghai Cancer Center, Shanghai, People's Republic of China \\ ${ }^{3}$ Department of Oncology, Shanghai Medical College, Fudan University, Shanghai, People's Republic of China \\ ${ }^{4}$ Department of Thoracic Surgery, Minhang Hospital, Fudan University, Shanghai, People's Republic of China \\ * These authors have contributed equally to this work \\ Correspondence to: Weiyan Liu, email: weiyanliufudan@163.com
}

Daowen Jiang, email: daowenjiangfudan@163.com

Keywords: gastric cancer, marital status, SEER, survival analysis

Received: October 20, $2015 \quad$ Accepted: January 24, 2016

Published: January 31, 2016

\section{ABSTRACT}

Marital status was found to be an independent prognostic factor for survival in various cancer types, but it hasn't been studied in gastric cancer. The Surveillance, Epidemiology and End Results database was used to compare survival outcomes with marital status. A total of 16,106 eligible patients were identified. Patients in the widowed group had the highest proportion of women, more common site of stomach, more prevalence of elderly patients, higher percentage of adenocarcinoma, and more tumors at localized stage $(P<0.05)$. Patients in married group had better $5 y e a r$ cause-specific survival (CSS) than those unmarried $(P<0.05)$. Further analysis showed that widowed patients always presented the lowest CSS compared with that of other groups. Widowed patients had $7.1 \%$ reduction in 5-year CSS compared with married patients at Localized stage $(77.2 \%$ vs $70.1 \%, P<0.001), 9.6 \%$ reduction at Regional stage (38.2\% vs $28.6 \%, P<0.001)$, and $4.7 \%$ reduction at Distant stage $(13.3 \%$ vs $8.6 \%, P<0.001)$. These results showed that unmarried patients were at greater risk of cancer specific mortality. Despite favorable clinicpathological characteristics, widowed patients were at highest risk of death compared with other groups.

\section{INTRODUCTION}

Gastric cancer represents a major cause of cancer mortality because of its poor prognosis [1]. The only potentially curative treatment for gastric cancer is complete resection (R0). However, even after surgical management, the 5 -year overall survival rate is only about $20 \%$ in series from the United States [2]. Several parameters could be used to predict survival outcomes in patients with gastric, including clinicopathological factors, adjuvant therapy, socioeconomic status, and psychiatric supports, such as, marital status. Married persons enjoy overall better health and increased life expectancy compared with the unmarried (divorced, separated, never married) [3-5].
Researches also indicate a survival advantage for married persons living with a chronic disease such as cancer. Accumulated studies have shown that marital status is an independent prognostic factor of survival in various cancer types [6-12]. In a larger population-based study on data from the Surveillance, Epidemiology and End Results (SEER) database indicated that unmarried patients are at significantly higher risk of presentation with metastatic cancer, undertreatment, and death resulting from their cancer in ten leading causes of cancer-related death [6]. To our knowledge, the impact of marital status on gastric cancer survival has not been previously studied. Data does exist to suggest that divorce, widowhood, and living alone increase the risk of each subtype of esophageal and 
Table 1: Baseline demographic and tumor characteristics of patients in SEER database.

\begin{tabular}{|c|c|c|c|c|c|c|}
\hline & Total & Married & Widowed & Single & $\begin{array}{l}\text { Divorced/ } \\
\text { Separated }\end{array}$ & $P$ value \\
\hline \multirow[t]{2}{*}{ Characteristic } & $(n=16106)$ & $(n=10273)$ & $(n=2349)$ & $(n=2072)$ & $(n=1412)$ & \\
\hline & & $\mathbf{N}(\%)$ & $\mathbf{N}(\%)$ & $\mathbf{N}(\%)$ & $\mathbf{N}(\%)$ & \\
\hline Sex & & & & & & $<0.001$ \\
\hline Male & 10178 & $7465(72.7)$ & $684(29.1)$ & $1253(60.5)$ & $776(55.0)$ & \\
\hline Female & 5928 & $2808(27.3)$ & $1665(70.9)$ & $819(39.5)$ & $636(45.0)$ & \\
\hline Primary Site & & & & & & $<0.001$ \\
\hline Stomach & 11638 & $7087(69.0)$ & $1986(84.5)$ & $1568(75.7)$ & $997(70.6)$ & \\
\hline Gastroesophageal Junction & 5928 & $3186(31.0)$ & $363(15.5)$ & $504(24.3)$ & $415(29.4)$ & \\
\hline Age & & & & & & $<0.001$ \\
\hline$\leqq 60$ & 5191 & $3505(34.1)$ & $106(4.5)$ & $1028(49.6)$ & $552(39.1)$ & \\
\hline$>60$ & 10915 & $6768(65.9)$ & $2243(95.5)$ & $1044(50.4)$ & $860(60.9)$ & \\
\hline Race & & & & & & $<0.001$ \\
\hline White & 10869 & $7090(69.0)$ & $1552(66.1)$ & $1280(61.8)$ & $947(67.1)$ & \\
\hline Black & 2007 & $884(8.6)$ & $342(14.6)$ & $510(24.6)$ & $271(19.2)$ & \\
\hline Other* & 3177 & $2263(22.0)$ & $448(19.1)$ & $279(13.5)$ & $187(13.2)$ & \\
\hline Unknown & 53 & $36(0.4)$ & $7(0.3)$ & $3(0.1)$ & $7(0.5)$ & \\
\hline \multicolumn{2}{|l|}{ Pathological grading } & & & & & $<0.001$ \\
\hline $\mathrm{I} / \mathrm{II}$ & 5179 & $3234(31.5)$ & $862(36.7)$ & $634(30.6)$ & $449(31.8)$ & \\
\hline III/ IV & 9880 & $6362(61.9)$ & $1354(57.6)$ & $1290(62.3)$ & $874(61.9)$ & \\
\hline Unknown & 1047 & $677(6.6)$ & $133(5.7)$ & $148(7.1)$ & $89(6.3)$ & \\
\hline Histotype & & & & & & $<0.001$ \\
\hline Adenocarcinoma & 12047 & $7659(74.6)$ & $1883(80.2)$ & $1466(70.8)$ & $1039(73.6)$ & \\
\hline Mucinous/Signet ring cell & 4059 & $2614(25.4)$ & $466(19.8)$ & $606(29.2)$ & $373(26.4)$ & \\
\hline SEER stage & & & & & & $<0.001$ \\
\hline Localized & 5621 & $3530(34.4)$ & $930(39.6)$ & $671(32.4)$ & $490(34.7)$ & \\
\hline Regional & 7723 & $4966(48.3)$ & $1062(45.2)$ & $1024(49.4)$ & $671(47.5)$ & \\
\hline Distant & 2578 & $1665(16.2)$ & $330(14.0)$ & $347(16.7)$ & $236(16.7)$ & \\
\hline Unstaged & 184 & $112(1.1)$ & $27(1.1)$ & $30(1.4)$ & $15(1.1)$ & \\
\hline
\end{tabular}

*: Other includes American Indian/Alaska native, Asian/Pacific Islander, etc 
gastric cancer [13], however, the analysis has not been extended to cancer outcome. Given that gastric cancer is one of the most common malignancies with high cancerrelated deaths and marriage is an important aspect of adult life, it is important to explore the relationship between marital status and gastric cancer survival outcomes and the potential underlying mechanisms. In this study, we used data from the SEER cancer-registry program of individuals diagnosed between 2004 and 2012 to explore the impact of marital status on gastric cancer cause specific survival (CSS) in patients after surgical resection.
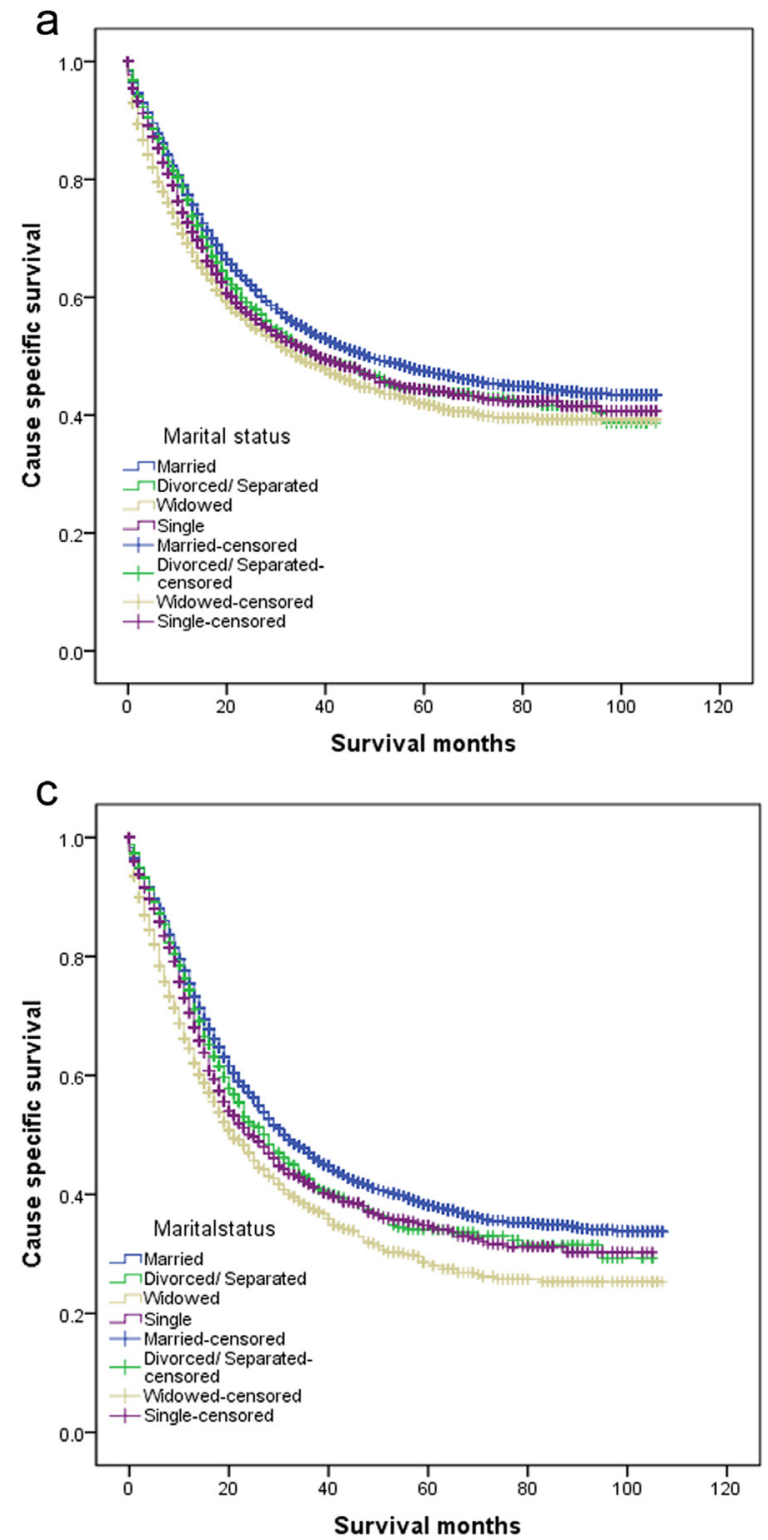

\section{RESULTS}

\section{Patient baseline characteristics}

A total of 16,106 eligible patients were identified during the 9-year study period, including 10,178 male and 5,928 female patients. Of these, 10,273 (63.8\%) were married, 2,349 (14.6\%) were widowed, and 2,072(12.9\%) were single. The $175(1.1 \%)$ individuals who were separated and 1,237(7.7\%) who were divorced were grouped together in the divorced/separated group in our study [11]. Patients in the widowed group had the highest proportion of women, more common site of stomach, more prevalence of elderly patients ( $>60$ years), and
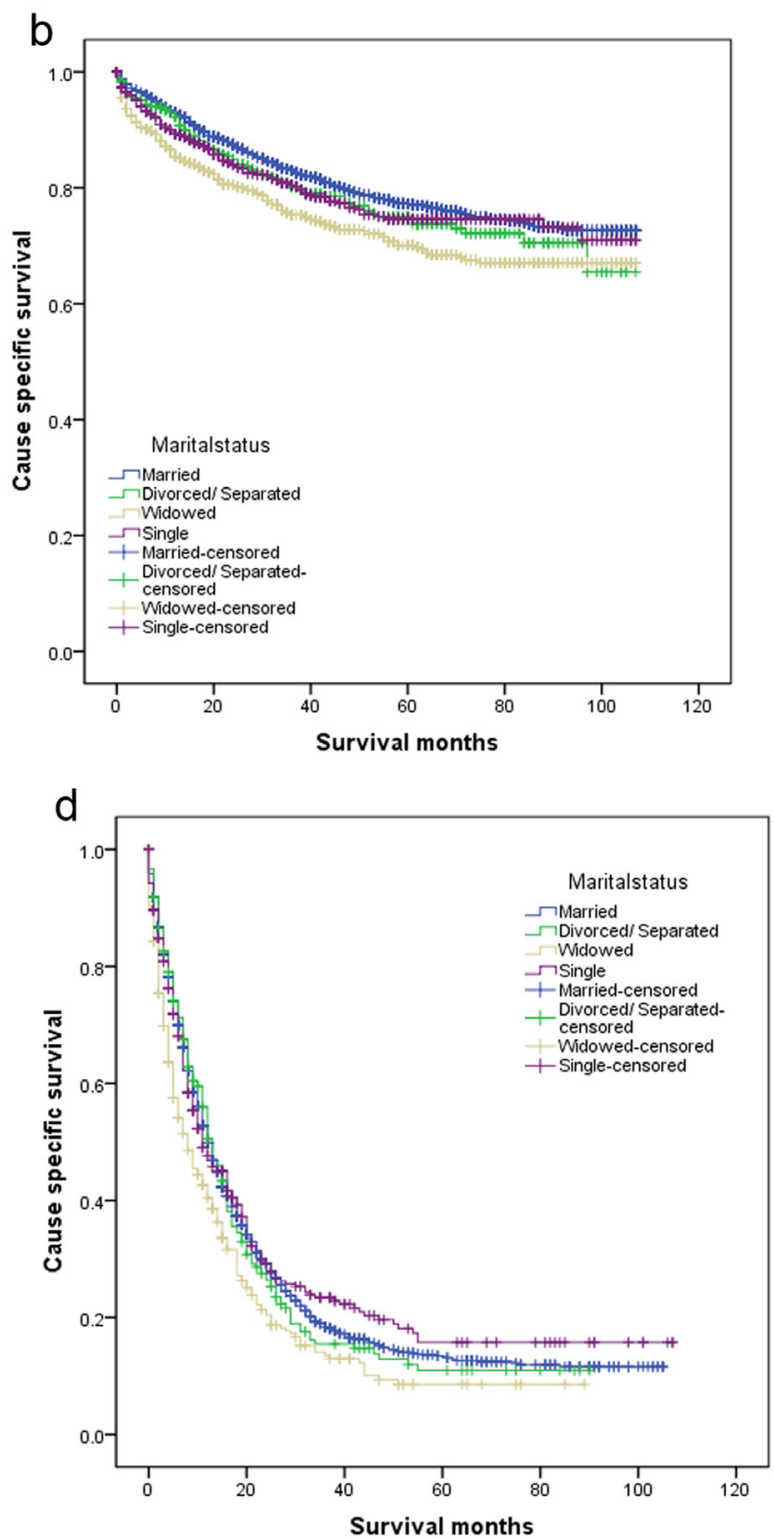

Figure 1: Survival curves in gastric patients according to marital status. a. All stage; $\chi^{2}=49.006, P<0.001$; b. Localized: $\chi^{2}$ $=25.356, P<0.001$; c. Regional: $\chi^{2}=54.197, P<0.001$; d. Distant: $\chi^{2}=20.161, P<0.001$. 
Table 2: Univariate and multivariate survival analysis for evaluating the influence of marital status on gastric cancer cause-specific survival in SEER database.

\begin{tabular}{|c|c|c|c|c|c|}
\hline \multirow[b]{2}{*}{ Variable } & \multirow[b]{2}{*}{ 5-year CCS } & \multicolumn{2}{|c|}{ Univariate analysis } & \multicolumn{2}{|c|}{ Multivariate analysis } \\
\hline & & Log rank $\chi^{2}$ test & $P$ & HR(95\%CI) & $P$ \\
\hline Primary Site & & 4.460 & 0.035 & & 0.881 \\
\hline Stomach & $46.5 \%$ & & & Reference & \\
\hline Gastroesophageal Junction & $44.6 \%$ & & & $1.004(0.949-1.062)$ & \\
\hline Sex & & 1.515 & 0.218 & & NI \\
\hline Male & $46.0 \%$ & & & & \\
\hline Female & $46.0 \%$ & & & & \\
\hline Age & & 10.218 & 0.001 & & $<0.001$ \\
\hline$\leqq 60$ & $46.2 \%$ & & & Reference & \\
\hline$>60$ & $46.9 \%$ & & & $1.339(1.269-1.412)$ & \\
\hline Race & & 87.890 & $<0.001$ & & \\
\hline White & $44.1 \%$ & & & Reference & $<0.001$ \\
\hline Black & $43.1 \%$ & & & $1.045(0.971-1.123)$ & \\
\hline Other* & $54.1 \%$ & & & $0.785(0.735-0.839)$ & \\
\hline Grade & & 518.723 & $<0.001$ & & $<0.001$ \\
\hline I / II & $59.2 \%$ & & & Reference & \\
\hline III/ IV & $38.2 \%$ & & & $1.430(1.349-1.517)$ & \\
\hline Unknown & $56.9 \%$ & & & $1.208(1.074-1.358)$ & \\
\hline Histotype & & 160.754 & $<0.001$ & & $<0.001$ \\
\hline Adenocarcinoma & $49.2 \%$ & & & Reference & \\
\hline Mucinous/signet ring cell & $36.8 \%$ & & & $1.175(1.113-1.241)$ & \\
\hline SEER Stage & & 3309.783 & $<0.001$ & & $<0.001$ \\
\hline Localized & $75.6 \%$ & & & Reference & \\
\hline Regional & $36.1 \%$ & & & $3.379(3.153-3.622)$ & \\
\hline Distant & $12.8 \%$ & & & $7.269(6.725-7.857)$ & \\
\hline Unstaged & $36.6 \%$ & & & $3.473(2.781-4.3361)$ & \\
\hline Marital Status & & 49.006 & $<0.001$ & & $<0.001$ \\
\hline Married & $47.5 \%$ & & & Reference & \\
\hline Windowed & $42.0 \%$ & & & $1.127(1.205-1.382)$ & \\
\hline Never married & $44.4 \%$ & & & $1.290(1.205-1.382)$ & \\
\hline Divorced/Separated & $44.4 \%$ & & & $1.082(0.994-1.179)$ & \\
\hline
\end{tabular}

*: Other includes American Indian/Alaska native, Asian/Pacific Islander, and unknown.

NI: not included in the multivariate survival analysis.

more tumors at Localized stage, higher percentage of adenocarcinoma, all of which were statistically significant $(P<0.001)$.Patient demographics and pathological features are summarized in Table 1.

\section{Effect of marital status on CSS in the SEER database}

The overall 5-year CSS was $47.5 \%$ in the married group, $42.0 \%$ in the widowed group, $44.4 \%$ in the never married group, and $44.4 \%$ in the divorced/separated group, which were all significantly different according to the univariate log-rank test $(P<0.001)$ (Table 2 , Figure 1a). Additionally, tumor located at gastroesophageal junction $(P=0.035)$, elderly patients $(P=0.001)$, male sex $(P<0.001)$, black ethnicity $(P<0.001)$, poor or undifferentiated tumor grade $(P<0.001)$, mucinous/ signet-ring cancer $(P<0.001)$, and advanced SEER stage $(P<0.001)$ were identified as significant risk factors for poor survival on univariate analysis (Table 2 ).

When multivariate analysis with Cox regression was 
Table 3: Univariate and multivariate analysis of marital status on gastric cancer cause specific survival based on different cancer stage.

\begin{tabular}{|c|c|c|c|c|c|}
\hline \multirow[b]{2}{*}{ Variable } & \multirow[b]{2}{*}{ 5-year CCS } & \multicolumn{2}{|c|}{ Univariate analysis } & \multicolumn{2}{|c|}{ Multivariate analysis } \\
\hline & & Log rank $\chi^{2}$ test & $P$ & HR(95\%CI) & $\boldsymbol{P}$ \\
\hline \multicolumn{6}{|l|}{ SEER Stage } \\
\hline \multicolumn{6}{|l|}{ Localized } \\
\hline Marital status & & 25.356 & $<0.001$ & & \\
\hline Married & $77.2 \%$ & & & Reference & \\
\hline Widowed & $70.1 \%$ & & & $1.411(1.202-1.655)$ & $<0.001$ \\
\hline Never married & $74.6 \%$ & & & $1.185(0.974-1.442)$ & 0.090 \\
\hline Divorced/Separated & $75.0 \%$ & & & $1.136(0.915-1.410)$ & 0.247 \\
\hline \multicolumn{6}{|l|}{ Regional } \\
\hline Marital status & & 54.197 & $<0.001$ & & \\
\hline Married & $38.2 \%$ & & & Reference & \\
\hline Widowed & $28.6 \%$ & & & $1.267(1.156-1.388)$ & $<0.001$ \\
\hline Never married & $34.8 \%$ & & & $1.181(1.073-1.301)$ & $<0.001$ \\
\hline Divorced/separated & $34.1 \%$ & & & $1.081(0.964-1.213)$ & 0.184 \\
\hline \multicolumn{6}{|l|}{ Distant } \\
\hline Marital status & & 20.161 & $<0.001$ & & \\
\hline Married & $13.3 \%$ & & & Reference & \\
\hline Widowed & $8.6 \%$ & & & $1.226(1.065-1.411)$ & 0.005 \\
\hline Never married & $15.7 \%$ & & & $1.001(0.868-1.155)$ & 0.984 \\
\hline Divorced/separated & $11.0 \%$ & & & $1.049(0.894-1.231)$ & 0.557 \\
\hline
\end{tabular}

P-values refer to comparisons between two groups and were adjusted for primary site, age, race, pathological grading, and tumor histologic type as covariates.

NI: not included in the multivariate survival analysis.

performed, six variables were validated as independent prognostic factors, including age $(>60$ years, hazard ratio (HR) 1.339, $95 \%$ confidence interval (CI) 1.269-1.412), race(black, HR 1.045,95\%CI 0.971-1.123; others, HR 0.785, 95\%CI 0.735-0.839), pathological grading(Grade III/IV , HR 1.430, 95\% CI 1.349-1.517; unknown, HR 1.208, $95 \%$ CI 1.074-1.358),histologic type (mucinous/ signet ring cell, HR 1.175, 95\% CI 1.113-1.241), SEER stage(Regional, HR 3.379 , 95\% CI 3.153-3.622; Distant, HR 7.269, 95\% CI 6.725-7.857; Unstaged, HR 3.473, 95\% CI 2.781-4.361), marital status(widowed, HR 1.290,95 \%CI 1.205-1.382; single, HR 1.127,95 \%CI 1.048-1.213; divorced/separated, HR1.082, 95\% CI 0.994-1.179).

\section{Subgroup analysis for evaluating the effect of marital status according to SEER stage}

We then made further analysis of the effects of marital status on survival in each tumor stage. We observed three interesting findings. First, marital status was an independent prognostic factor in each tumor stage both in univariate and multivariate analysis $(P<0.05)$. Second, patients in the widowed group always had the lowest survival rate when compared with patients in the other groups. Widowed patients had $7.1 \%$ reduction in 5-year CSS compared with married patients at Localized stage $(77.2 \%$ vs $70.1 \%, P<0.001), 9.6 \%$ reduction at Regional stage II (38.2\% vs 28.6\%, $P<0.001)$, and $4.7 \%$ reduction at Distant stage $(13.3 \%$ vs $8.6 \%, P<0.001)$. Third, the difference between the divorced/separated and married group was not apparent in all stage. (Table 3, Figure 1b-1d).

\section{DISCUSSION}

This study is the first to show an independent beneficial effect of marriage on survival in gastric cancer. The beneficial effect of being married persisted even after being adjusted for stage, age, histologic type, and grade in multivariable analyses. Moreover, widowed patients were always most likely to die of gastric cancer than other groups. Specifically, patients in the widowed group had 
more common site of stomach, more tumors at localized stage, and higher percentage of adenocarcinoma, all of which were validated as protective prognosis factors in survival analysis. Interestingly, delayed diagnosis was considered as another reason for poor prognosis in unmarried patients $[6,14,15]$. However, in our study group, the percentage of patients with gastric in Localized stage was highest in the widowed group with $39.6 \%$ compared with $34.4 \%, 32.4 \%$, and $34.7 \%$ in the married, single, and divorced/separated group, respectively. Obviously, this result is paradoxical given the poor survival outcomes in the widowed group.

Our data revealed that unmarried patients had a survival disadvantage that persisted in each SEER stage. The relationship between marital status and survival can be explained hypothetically by psychosocial factors that are independent of tumor characteristics and extent of treatment. Depression has been reported widely existing among cancer patients [16-18]. Depressive disorders affect up to $38 \%$ of patients with cancer, worsen over the course of treatment, persist long after cancer therapy has concluded, and often reappear on cancer recurrence $[19,20]$. The prevalence of depression was high in stomach cancer patients even after the completion of treatment, especially among those with problems amenable to treatment [21]. It has been proposed that decreased psychosocial support and psychological stress alter immune function and contribute to tumor progression and mortality [22-24]. Levy et al. reported that a perceived lack of social support was associated with lower activity of natural killer cells [25]. Chronic stress may elicit prolonged secretion of cortisol [26], which triggers a counterregulatory response of white blood cells by downregulating their cortisol receptors. This downregulation, in turn, reduces the cells' capacity to respond to anti-inflammatory signals and allows cytokinemediated inflammatory processes to flourish [27], which have been validated as poor prognostic factors in gastric cancer [28, 29].Conversely, cortisol levels seem to be lower in patients with cancer who have adequate support networks, and diurnal cortisol patterns have been linked with natural-killer cell count and survival in patients with cancer [30, 31]. Additionally, depression and quality of life are related to VEGF, which may stimulate endothelial cell migration, proliferation and proteolytic activity [32]. Unrecognized clinical depression is strongly associated with poor adherence to medical treatment [33]. To date, two prospective studies regarding the association between depression and survival in patients with gastric cancer have been reported $[34,35]$. Chen et al. found subjects with higher depression scores had an poor survival compared with the subjects with lower scores [34].Yu et al. followed 300 patients with gastric cancer and found mortality were higher in patients with depression [35]. The loss of social support or the inability to cope with stress in the widowed groups seems very apparent, and may lead to excess mortality [36, 37].

The results of this study must be interpreted in the light of certain limitations. First, the SEER database only provides the marital status at diagnosis. There is potential for misclassification of marital status. We did not take into account changes of marital status that may have occurred during the follow-up period, which may have influenced outcomes. Thus, our findings may underestimate the protective effect marriage has on gastric cancer outcome. Second, SEER database lacks information of education, income status, insurance status, socioeconomic status and quality of marriage, which might confound the explanation of the disparity in survival between marital groups. For example, marital distress has long-term immune consequences and enhances the risk of a variety of health problems [38]. Third, information on therapy options (radical resection or palliative therapy), subsequent therapy, co-morbidities and recurrence is also lacking.

Despite these potential limitations, results of our study confirmed that unmarried patients are at greater risk of cancer-specific mortality. Especially, widowed patients were always at the highest risk of death of cancer than those in other groups. We concluded that much of the benefit enjoyed by married women is derived from intrinsic social support and social networks. The value of this finding is that social support may well be amenable to intervention and may lead to improved outcomes [39]. Health care providers should recognize that the unmarried patients are at particular risk with respect to treatment of, and survival from gastric cancer. These patients may require more counseling and comprehensive case management.

\section{MATERIALS AND METHODS}

\section{Patient selection in the SEER database}

Frequency and survival data were obtained from the SEER Program database using SEER*Stat 8.1.5 software (National Cancer Institute, Bethesda, MD); specifically, the SEER 18 dataset (consisting of 18 registries, covering the years (2004-2012) was used. The current SEER database consists of 18 population-based cancer registries that represent approximately $28 \%$ of the population in the US. It uncover sensitive patient information and is widely used for studies of the relationship between marital status and survival outcomes of patients with cancer $[6,7,9,11$, 40, 41].

Using the SEER-stat software (SEER*Stat 8.1.5), we searched for patients diagnosed between 2004 and 2012 with single primary gastric cancer and a known marital status. Histological types were limited to adenocarcinoma, mucinous adenocarcinoma, and signet ring cell carcinoma. Patients were excluded if age at diagnosis was less than 
18 years, had more than one primary cancer but the gastric wasn't the first one, had no surgical resection, had unknown cause of death or unknown survival months.

\section{Statistical analysis}

Data was analyzed based on age, gender, race, histologic grade, tumor location, extent of disease, and treatment (surgical resection or not). Race was divided into white, black, and others. According to the SEER staging system, tumors that remain in situ or confined to the organ are regarded as localized. Those that locally invade or metastasize to regional lymph nodes are considered to be regional, whereas those that travel to distant organs are categorized as distant. Within the SEER database, marital status of the patient is recorded at the time of diagnosis. Marital status is coded as married, divorced, widowed, separated, never married, and unmarried or Domestic Partner. Individuals in the separated and divorced group were clustered together as the divorced/separated group, never married, and unmarried or Domestic Partner were grouped as single group in this study.

Patient baseline characteristics were compared with the $\chi^{2}$ test, as appropriate. The rate of death was compared between groups using the Kaplan-Meier method. Multivariable Cox regression models were built for analysis of risk factors for survival outcomes. The primary endpoint of this study was CSS, which was calculated from the date of diagnosis to the date of cancer specific death. Deaths attributed to gastric cancer were treated as events and deaths from other causes were treated as censored observations. All of statistical analyses were performed using the statistical software package SPSS for Windows, version 17 (SPSS Inc, Chicago, IL, USA). Statistical significance was set at two-sided $P<0.05$.

\section{ACKNOWLEDGMENTS}

The authors acknowledge the efforts of the Surveillance, Epidemiology, and End Results (SEER) Program tumor registries in the creation of the SEER database. The interpretation and reporting of these data are the sole responsibility of the authors.

This study was partially supported by grants from the Shanghai Municipal Health Bureau Project (No:20134406).

\section{Authors' contributions}

RLS, QC, DWJ and WYL conceived of and designed the study. ZY, ZPZ and GFP performed the analyses. WHW, SQL and DBZ prepared all figures and tables. RLS, QC, DWJ and WYL wrote the main manuscript. All authors reviewed the manuscript.

\section{CONFLICTS OF INTERESTS}

None of the authors have any conflict of interest to declare.

\section{REFERENCES}

1. Torre LA, Bray F, Siegel RL, Ferlay J, Lortet-Tieulent J and Jemal A. Global cancer statistics, 2012. CA Cancer J Clin. 2015; 65:87-108.

2. Macdonald JS. Gastric cancer - new therapeutic options. N Engl J Med. 2006; 355:76-77.

3. Kaplan RM and Kronick RG. Marital status and longevity in the United States population. Journal of epidemiology and community health. 2006; 60:760-765.

4. Hu YR and Goldman N. Mortality differentials by marital status: an international comparison. Demography. 1990; 27:233-250.

5. Ikeda A, Iso H, Toyoshima H, Fujino $\mathrm{Y}$, Mizoue $\mathrm{T}$, Yoshimura T, Inaba Y, Tamakoshi A and Group JS. Marital status and mortality among Japanese men and women: the Japan Collaborative Cohort Study. BMC public health. 2007; 7:73.

6. Aizer AA, Chen MH, McCarthy EP, Mendu ML, Koo S, Wilhite TJ, Graham PL, Choueiri TK, Hoffman KE, Martin NE, Hu JC and Nguyen PL. Marital status and survival in patients with cancer. J Clin Oncol. 2013; 31:3869-3876.

7. Denberg TD, Beaty BL, Kim FJ and Steiner JF. Marriage and ethnicity predict treatment in localized prostate carcinoma. Cancer. 2005; 103:1819-1825.

8. Torssander J and Erikson R. Marital partner and mortality: the effects of the social positions of both spouses. Journal of epidemiology and community health. 2009; 63:992-998.

9. Nelles JL, Joseph SA and Konety BR. The impact of marriage on bladder cancer mortality. Urologic oncology. 2009; 27:263-267.

10. Johansen C, Schou G, Soll-Johanning H, Mellemgaard A and Lynge E. Influence of marital status on survival from colon and rectal cancer in Denmark. Br J Cancer. 1996; 74:985-988.

11. Wang L, Wilson SE, Stewart DB and Hollenbeak CS. Marital status and colon cancer outcomes in US Surveillance, Epidemiology and End Results registries: does marriage affect cancer survival by gender and stage? Cancer epidemiology. 2011; 35:417-422.

12. Li Q, Gan L, Liang L, Li X and Cai S. The influence of marital status on stage at diagnosis and survival of patients with colorectal cancer. Oncotarget. 2015; 6:7339-7347. doi: 10.18632/oncotarget.3129.

13. Lagergren J, Andersson G, Talback M, Drefahl S, Bihagen E, Harkonen J, Feychting M and Ljung R. Marital status, education, and income in relation to the risk of esophageal and gastric cancer by histological type and site. Cancer. 2016; 122:207-12. 
14. Osborne C, Ostir GV, Du X, Peek MK and Goodwin JS. The influence of marital status on the stage at diagnosis, treatment, and survival of older women with breast cancer. Breast cancer research and treatment. 2005; 93:41-47.

15. Nayeri K, Pitaro G and Feldman JG. Marital status and stage at diagnosis in cancer. New York state journal of medicine. 1992; 92:8-11.

16. Tsunoda A, Nakao K, Hiratsuka K, Yasuda N, Shibusawa $\mathrm{M}$ and Kusano M. Anxiety, depression and quality of life in colorectal cancer patients. International journal of clinical oncology. 2005; 10:411-417.

17. Bodurka-Bevers D, Basen-Engquist $\mathrm{K}$, Carmack CL, Fitzgerald MA, Wolf JK, de Moor C and Gershenson DM. Depression, anxiety, and quality of life in patients with epithelial ovarian cancer. Gynecologic oncology. 2000; 78:302-308.

18. Alacacioglu A, Yavuzsen T, Dirioz M and Yilmaz U. Quality of life, anxiety and depression in Turkish breast cancer patients and in their husbands. Med Oncol. 2009; 26:415-419.

19. Miovic M and Block S. Psychiatric disorders in advanced cancer. Cancer. 2007; 110:1665-1676.

20. Honda K and Goodwin RD. Cancer and mental disorders in a national community sample: findings from the national comorbidity survey. Psychotherapy and psychosomatics. 2004; 73:235-242.

21. Han KH, Hwang IC, Kim S, Bae JM, Kim YW, Ryu KW, Lee JH, Noh JH, Sohn TS, Shin DW and Yun YH. Factors associated with depression in disease-free stomach cancer survivors. Journal of pain and symptom management. 2013; 46:511-522.

22. Garssen B and Goodkin K. On the role of immunological factors as mediators between psychosocial factors and cancer progression. Psychiatry research. 1999; 85:51-61.

23. Sklar LS and Anisman H. Stress and coping factors influence tumor growth. Science. 1979; 205:513-515.

24. Moreno-Smith M, Lutgendorf SK and Sood AK. Impact of stress on cancer metastasis. Future oncology. 2010; 6:18631881.

25. Levy SM, Herberman RB, Whiteside T, Sanzo K, Lee J and Kirkwood J. Perceived social support and tumor estrogen/ progesterone receptor status as predictors of natural killer cell activity in breast cancer patients. Psychosomatic medicine. 1990; 52:73-85.

26. McEwen BS. Physiology and neurobiology of stress and adaptation: central role of the brain. Physiological reviews. 2007; 87:873-904.

27. Miller GE, Cohen S and Ritchey AK. Chronic psychological stress and the regulation of pro-inflammatory cytokines: a glucocorticoid-resistance model. Health psychology. 2002; 21:531-541.

28. Wang SC, Chou JF, Strong VE, Brennan MF, Capanu M and Coit DG. Pretreatment Neutrophil to Lymphocyte Ratio Independently Predicts Disease-specific Survival in Resectable Gastroesophageal Junction and Gastric Adenocarcinoma. Ann Surg. 2016; 263:292-7.

29. Qu JL, Qu XJ, Li Z, Zhang JD, Liu J, Teng YE, Jin B, Zhao MF, Yu P, Shi J, Fu LY, Wang ZN and Liu YP. Prognostic Model Based on Systemic Inflammatory Response and Clinicopathological Factors to Predict Outcome of Patients with Node-Negative Gastric Cancer. PLoS One. 2015; 10:e0128540.

30. Sephton SE, Lush E, Dedert EA, Floyd AR, Rebholz WN, Dhabhar FS, Spiegel D and Salmon P. Diurnal cortisol rhythm as a predictor of lung cancer survival. Brain, behavior, and immunity. 2013; 30 Suppl:S163-170.

31. Sephton SE, Sapolsky RM, Kraemer HC and Spiegel D. Diurnal cortisol rhythm as a predictor of breast cancer survival. J Natl Cancer Inst. 2000; 92:994-1000.

32. Ferrara $\mathrm{N}$ and Davis-Smyth $\mathrm{T}$. The biology of vascular endothelial growth factor. Endocrine reviews. 1997; 18:425.

33. DiMatteo MR, Lepper HS and Croghan TW. Depression is a risk factor for noncompliance with medical treatment: meta-analysis of the effects of anxiety and depression on patient adherence. Arch Intern Med. 2000; 160:2101-2107.

34. Chen YH and Lin HC. Increased risk of cancer subsequent to severe depression - a nationwide population-based study. Journal of affective disorders. 2011; 131:200-206.

35. Yu H, Wang Y, Ge X, Wu X and Mao X. Depression and survival in Chinese patients with gastric cancer: a prospective study. Asian Pac J Cancer Prev. 2012; 13:391394.

36. Martikainen P and Valkonen T. Mortality after the death of a spouse: rates and causes of death in a large Finnish cohort. American journal of public health. 1996; 86:1087-1093.

37. Li Q, Gan L, Liang L, Li X and Cai S. The influence of marital status on stage at diagnosis and survival of patients with colorectal cancer. Oncotarget. 2015; 6:7339-7347. doi: 10.18632/oncotarget.3129.

38. Jaremka LM, Glaser R, Malarkey WB and Kiecolt-Glaser JK. Marital distress prospectively predicts poorer cellular immune function. Psychoneuroendocrinology. 2013; 38:2713-2719.

39. Berkman LF. Social support, social networks, social cohesion and health. Social work in health care. 2000; 31:314.

40. Kravdal $\mathrm{H}$ and Syse A. Changes over time in the effect of marital status on cancer survival. BMC public health. 2011; 11:804.

41. Rippentrop JM, Joslyn SA and Konety BR. Squamous cell carcinoma of the penis: evaluation of data from the surveillance, epidemiology, and end results program. Cancer. 2004; 101:1357-1363. 